
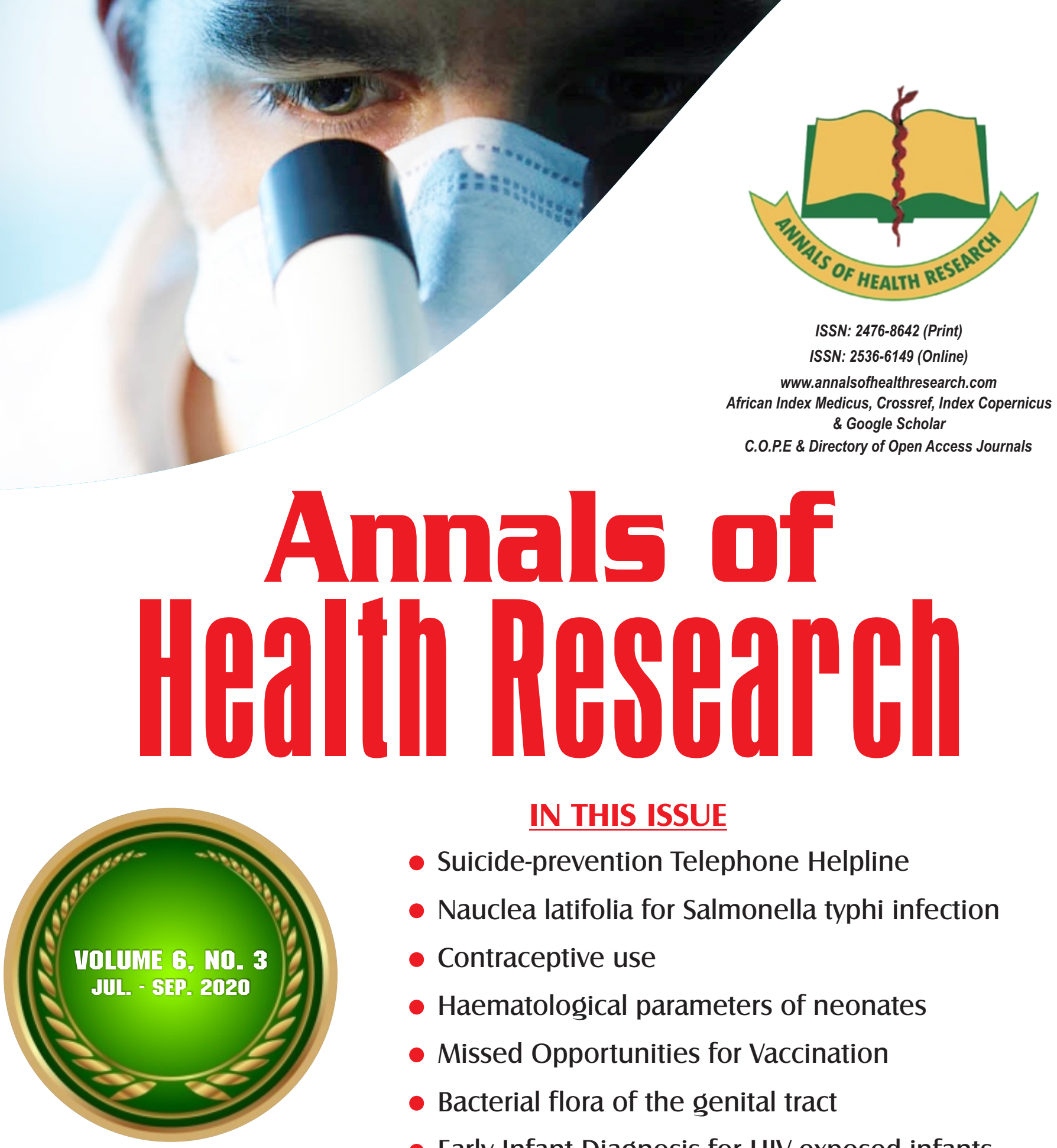

IN THIS ISSUE

- Suicide-prevention Telephone Helpline

- Nauclea latifolia for Salmonella typhi infection

- Contraceptive use

- Haematological parameters of neonates

- Missed Opportunities for Vaccination

- Bacterial flora of the genital tract

- Early Infant Diagnosis for HIV-exposed infants

- Bone markers and cardiovascular risk factors

- Attitude to termination of pregnancies

- Herpes zoster ophthalmicus

- Neonatal hyperinsulinaemic hypoglycaemia

- Paediatric perineal injury

PUBLISHED BY THE MEDICAL

AND DENTAL CONSULTANTS ASSOCIATION

OF NIGERIA, OOUTH, SAGAMU, NIGERIA.

www.mdcan.oouth.org.ng 


\section{Herpes zoster ophthalmicus at a tertiary health facility, South-western Nigeria: Clinical presentations and outcome Fasina $\mathrm{O}^{* 1,2}$, Hughes $\mathrm{SJ}^{2}$ \\ 1Department of Ophthalmology, University of Ibadan, Ibadan, Nigeria ${ }^{2}$ Department of Ophthalmology, University College Hospital, Ibadan, Nigeria}

*Correspondence: Dr O. Fasina, Department of Ophthalmology, University of Ibadan, Ibadan, Nigeria. E-mail: yemifash2000@yahoo.com; ORCID - https://orcid.org/0000-0002-4386-527X.

\section{Summary}

Herpes zoster ophthalmicus is a neurocutaneous disease caused by the human alpha herpes virus Type 3 and it is characterized by reactivation of dormant varicella-zoster virus lying within the trigeminal ganglia. The objective of this study was to describe the clinical presentation and management outcome of patients with herpes zoster ophthalmicus in a tertiary health facility. This was a retrospective study of patients with herpes zoster ophthalmicus managed at the Eye Clinic of a tertiary health facility in the South-western part of Nigeria over eight years. There were 17 patients, comprising five males and the mean age at presentation was $54.9 \pm 13.7$ years. Seven $(41.2 \%)$ patients were seropositive for the Human Immunodeficiency Virus (HIV) while nine (52.9\%) patients had corneal involvement. Fifteen $(88.2 \%)$ patients had involvement of the first branch of the trigeminal nerve $\left(V_{1}\right)$, and one $(5.9 \%)$ patient each had involvement of the second branch of the trigeminal nerve $\left(V_{2}\right)$ and the first two branches of the trigeminal nerve $\left(\mathrm{V}_{1}\right.$ and $\left.\mathrm{V}_{2}\right)$. All the patients were managed with oral and topical antiviral medications. Ten patients (58.8\%) developed postherpetic neuralgia. In conclusion, Herpes zoster ophthalmicus is strongly associated with HIV seropositivity and older age and a significant proportion of patients develop post-herpetic neuralgia necessitating long term management.

Keywords: Herpes simplex, Herpes Zoster Ophthalmicus, Human Immunodeficiency Virus, Postherpetic neuralgia, Nigeria.

\section{Introduction}

Herpes zoster ophthalmicus (HZO) is a neurocutaneous disease caused by the human alpha Herpes virus Type 3, referred to as the Varicella-Zoster Virus. It is a member of the herpes virus family known as Herpes viridae, which are DNA viruses that cause infections in humans. [1] It is characterized by the reactivation of dormant varicella-zoster virus lying within the trigeminal ganglia and is commonly seen in the elderly and individuals with depressed cellular immunity, such as those on immunosuppressive therapy, treatment for lymphoma or HIV/AIDS. [2] Typically, patients present with painful dermatomal rash involving the ophthalmic division of the trigeminal nerve. [1] There are some studies [3-9] on herpes zoster ophthalmicus in Nigeria but, to the best of the authors' knowledge, there are no published reports from Ibadan. The objective of this cases series was to highlight the clinical presentation and management outcome of patients with $\mathrm{HZO}$ at a tertiary health facility in Southwestern Nigeria. 


\section{Method}

This was a retrospective case review. The medical records of patients who were managed for $\mathrm{HZO}$ at the Eye Unit of the University College Hospital, Ibadan, southwestern Nigeria between August 2010 and July 2018 were retrieved from the Health Information Department of the hospital. The information retrieved from the case notes included socio-demographics, clinical presentation, duration of symptoms, systemic comorbidities, treatment, complications and period of follow-up care. The diagnosis of $\mathrm{HZO}$ was made based on the clinical features of typical vesicular or vesiculobullous skin eruptions or healing crusts on one half of the face along the dermatomal distribution of the trigeminal nerve. Ethical approval for the study was obtained from the Ethical Review Committee. The methodology also adhered to the tenets of the Declaration of Helsinki.

The data were entered into a computer, cleaned and analyzed with International Business Machines-compliant Statistical Package for the Social Sciences version 20 software (SPSS Inc, Chicago IL., USA). The data were analysed using simple descriptive statistics.

\section{Results}

A total of 17 patients were managed for $\mathrm{HZO}$ within eight years. These comprised 5 males and 12 females (with male to female ratio of 1 : 2.4 ). The mean age was $54.9 \pm 13.7$ years (range: 29-81yrs) as shown in Table I.

Seven $(41.2 \%)$ patients were seropositive for HIV and were receiving HAART. All the patients presented with vesicular or vesiculobullous facial rash while five patients (29.4\%) had tingling sensation and paraesthesia (Table I) Nine patients (52.9\%) had corneal involvement and presented with superficial epithelial punctate keratitis while $10(58.8 \%)$ patients had positive Hutchinson's sign. Fifteen patients $(88.2 \%)$ had involvement of only the ophthalmic $\left(\mathrm{V}_{1}\right)$ branch of the trigeminal nerve, while one $(5.9 \%)$ patient had involvement of both $\mathrm{V}_{1}$ and maxillary $\left(\mathrm{V}_{2}\right)$ branches and another one (5.9\%) had involvement of only $\mathrm{V}_{2}$ (Table I). Five (29.5\%) patients presented with corrected visual acuity of $\geq 6 / 12$, and at the last follow-up clinic visit, eight $(47.1 \%)$ patients had an acuity of $\geq 6 / 12$ (Table I).

All the patients were managed with both Acyclovir ointment applied topically five times daily over the rash in the acute phase of the disease, and oral acyclovir, 800mg five times daily for two weeks. Patients who had secondary superficial bacterial infection were treated with guttae Ciprofloxacin instilled into the eye four to six times daily and topical Chloramphenicol ointment applied at night. Those with corneal involvement were also treated with guttae atropine and ocular lubricants and all patients had resolution of their symptoms. Ten (58.8\%) patients developed post herpetic neuralgic pain. The patients were followed up for a period of 1-36 months with an average of 2.5 months (Interquartile range, 1 - 7 months).

\section{Discussion}

Herpes zoster ophthalmicus occurs in about 10 to $25 \%$ of patients with herpes zoster infection. [10] Primary infection with varicella-zoster virus clinically as chickenpox in childhood produces long-term immunity in an individual, and reactivation of the virus in the dorsal root ganglion of the trigeminal nerve depends on the level of cell-mediated immunity in an individual. [10] About half of the patients in this study were seropositive for HIV, similar to the findings from some previous studies in the country. [4, 9] The peak age at presentation in this cohort of patients was the sixth decade of life which is contrary to what was reported from other parts of the country. [3,5] 
Table I: Demographic and clinical characteristics and clinical presentations of the 17 patients

\begin{tabular}{|c|c|c|c|c|c|c|c|c|c|c|}
\hline $\mathrm{S} / \mathrm{N}$ & $\begin{array}{l}\text { Age } \\
\text { (years) }\end{array}$ & Sex & $\begin{array}{l}\text { HIV } \\
\text { status }\end{array}$ & $\begin{array}{l}\text { Presenting } \\
\text { VA }\end{array}$ & $\begin{array}{l}\text { Final } \\
\text { VA }\end{array}$ & $\begin{array}{l}\text { Branch } \\
\mathrm{CN}_{5} \\
\text { affected }\end{array}$ & $\begin{array}{l}\text { Tingling } \\
\text { sensation }\end{array}$ & $\begin{array}{l}\text { Hutchinson's } \\
\text { sign }\end{array}$ & $\begin{array}{l}\text { Corneal } \\
\text { involvement }\end{array}$ & PHN \\
\hline 1 & 58 & F & Positive & LP & LP & $\mathrm{V}_{1}$ & Yes & Yes & Yes & Yes \\
\hline 2 & 58 & F & Positive & $6 / 6$ & $6 / 6$ & $\mathrm{~V}_{2}$ & Yes & Yes & Yes & Yes \\
\hline 3 & 62 & F & Negative & $6 / 18$ & $6 / 9$ & $\mathrm{~V}_{1}$ & No & No & No & Yes \\
\hline 4 & 81 & $\mathrm{~F}$ & Negative & $\mathrm{CF}$ & $\mathrm{CF}$ & $\mathrm{V}_{1}$ & No & Yes & Yes & Yes \\
\hline 5 & 33 & F & Positive & $6 / 24$ & $6 / 18$ & $V_{1}+V_{2}$ & No & Yes & Yes & No \\
\hline 6 & 29 & $\mathrm{~F}$ & Negative & $6 / 12$ & $6 / 12$ & $\mathrm{~V}_{1}$ & No & No & No & No \\
\hline 7 & 68 & M & Negative & $\mathrm{LP}^{*}$ & $\mathrm{LP}^{*}$ & $\mathrm{~V}_{1}$ & No & No & No & Yes \\
\hline 8 & 40 & $\mathrm{~F}$ & Positive & $6 / 18$ & $6 / 9$ & $\mathrm{~V}_{1}$ & No & Yes & No & No \\
\hline 9 & 61 & M & Negative & CF & CF & $\mathrm{V}_{1}$ & No & Yes & Yes & Yes \\
\hline 10 & 55 & $\mathrm{~F}$ & Negative & $6 / 12$ & $6 / 9$ & $\mathrm{~V}_{1}$ & No & Yes & Yes & Yes \\
\hline 11 & 62 & M & Positive & LP & LP & $\mathrm{V}_{1}$ & Yes & Yes & Yes & No \\
\hline 12 & 38 & M & Positive & $6 / 24$ & $6 / 36$ & $\mathrm{~V}_{1}$ & Yes & No & Yes & No \\
\hline 13 & 56 & $\mathrm{~F}$ & Negative & $6 / 9$ & $6 / 9$ & $\mathrm{~V}_{1}$ & Yes & No & No & Yes \\
\hline 14 & 64 & $\mathrm{~F}$ & Negative & $6 / 9$ & $6 / 6$ & $\mathrm{~V}_{1}$ & No & Yes & No & Yes \\
\hline 15 & 52 & M & Positive & HM & $\mathrm{HM}$ & $\mathrm{V}_{1}$ & No & No & Yes & Yes \\
\hline 16 & 48 & $\mathrm{~F}$ & Negative & $6 / 24$ & $6 / 12$ & $\mathrm{~V}_{1}$ & No & Yes & No & No \\
\hline 17 & 68 & F & Negative & LP & LP & $\mathrm{V}_{1}$ & No & No & No & No \\
\hline
\end{tabular}

This may be explained partly by the fewer number of patients who were HIV-positive in the present series. HIV-seropositivity has been reported more commonly in individuals younger than 50 years. ${ }^{[5,6]}$ Other conditions causing immune compromise were not found in the present cohort of patients, similar to the report of Saka et al. [9] in another part of the country. A female predominance was noted in the present series, similar to the findings of Owoeye and co-workers. [4] This could be explained in part by the reported a higher prevalence of HIV infection among the female gender. [11]

The mean duration of symptoms in this series was 12.2 \pm 9.3 days. This fairly short duration of complaints before presentation to our facility, when compared with the known delayed pattern of pre-hospital consultation in the region, ${ }^{[12]}$ can be partly attributed to the acute severe pain associated with HZO. The commonest presenting symptom was vesicular or vesiculobullous rash involving the forehead and periocular region in line with the typical presentation of patients with $\mathrm{HZO}$. The other symptoms in the patients included eyelid swelling, scalp pain and ocular ache as previously reported in other studies. $[9,13]$

At presentation, about a third of the patients were blind (acuity $<3 / 60$ ), with another third having good vision (acuity $\geq 6 / 12$ ), and these levels of acuity were maintained after treatment. Of the seven patients presenting with mild to severe visual impairment (acuity $<6 / 12$ to $3 / 60$ ), three of them improved to good vision following treatment while the other four patients maintained their level of visual acuity. The major cause of visual affectation in our patients was corneal involvement, similar to the finding in the study by Kahloun et al., [14] who reported corneal involvement as the most common vision-threatening complication of $\mathrm{HZO}$ following corneal neovascularization, neurotrophic ulceration, secondary bacterial infection and scarring. More than half $(58.8 \%)$ of the patients presented with Hutchinson's sign, and greater than two-thirds of them had corneal involvement, while less than a third of those with negative Hutchinson's sign had corneal affectation. It has been reported that 
Hutchinson's sign is a strong predictor for ocular involvement in HZO. [15,16]

The ophthalmic branch $\left(\mathrm{V}_{1}\right)$ of the trigeminal nerve was most affected in this series, as recorded in about $90 \%$ of the patients with one patient each presenting with the involvement of only $V_{2}$ or a combination of $V_{1}$ and $V_{2}$ involvement. This pattern of nerve affectation is similar to the findings in other studies, $[5,9]$ as the herpes virus has been noted to have a predilection for the first branch of the trigeminal nerve. The involvement of the maxillary branch of the trigeminal nerve with accompanying keratitis is an uncommon presentation of the disease. ${ }^{[5]}$

The patients responded well to the range of therapies with the resolution of the acute phase of the infection. Antiviral therapy promotes the early resolution of the acute symptoms in patients with HZO. ${ }^{[9,17]}$ About a third of the patients developed postherpetic neuralgia of varying severity after the resolution of the acute phase of the illness, similar to the report of Umeh et al.[3] Post herpetic neuralgic pain was managed in conjunction with the neurologist using oral amitriptyline or pregabalin.

This study is limited in its retrospective design as investigations for some risk factors like syphilis were not carried out in all the patients, and clinical details of corneal affectation were not documented in many of the cases.

\section{Conclusion}

$\mathrm{HZO}$ is associated with HIV infection and older age group in south-western Nigeria and it mostly affects the $V_{1}$ branch of the trigeminal nerve. A great proportion of the patients may develop post-herpetic neuralgia necessitating long-term pain control treatment. Encouraging early care-seeking when affected and prompt commencement of appropriate treatment may reduce corneal complications and the resultant blindness.

Authors' Contributions: FO conceptualized the study, contributed to data collection and analysis, and drafted the manuscript. HSJ contributed to data collection and analysis, and the drafting of the manuscript. Both authors approved the final version of the manuscript.

Conflict of interest: None declared.

Funding: Self-funded.

Publication History: Submitted 06 January 2020; Accepted 16 May 2020.

\section{References}

1. Wiafe B. Herpes Zoster Ophthalmicus in HIV/AIDS. J Comm Eye Health 2003; 16: 35-36.

2. Liesegang TJ. Herpes Zoster Ophthalmicus natural history, risk factors, clinical presentation and morbidity. Ophthalmology 2008; 115: 3-12.

3. Umeh RE. Herpes zoster ophthalmicus and HIV infection in Nigeria. Int J STD AIDS 1998; 9: 476-479.

4. Owoeye JFA, Ademola-Popoola DS. Herpes zoster infection and HIV seropositivity among eye patients University of Ilorin Teaching Hospital experience. West Afr J Med 2003; 22: 136138.

5. Dawodu OA, Osahon AI, Alikah AA, Bakare C. Herpes zoster ophthalmicus. South Afr Med J 2005; 95: 30-31.

6. Akinsola FB, Okanny CC, Majekodunmi AA, Akinsete I. Ocular manifestations of HIV infections in Lagos: Lagos University Teaching Hospital experience. Niger Postgrad Med J 1997; 4: 84-87.

7. Nwosu SNN, Anyiwo CE, Nwosu MC. Herpes zoster ophthalmicus associated with HIV infections. A report of two cases. Niger Med J 1995; 281: 27-29.

8. Adio AO, Fiebai B. Herpes zoster ophthalmicus and HIV seropositivity in 
South-south Nigeria. Niger J Med 2010; 19: $162-164$

9. Saka ES, Olatunj FO, Monsudi KF, Balarabe AH, Qudus BA, Isa A. Herpes zoster ophthalmicus infection among eye patients- Federal Medical Centre Birni Kebbi, Kebbi state experience. J Med Res Clin Sci 2014; 2: 3293-3298.

10. Hodge WG, Seiff SR, Margolis TP. Ocular opportunistic infection incidences among patients who are HIV positive compared to patients who are HIV negative. Ophthalmology 1998; 105: 895-900.

11. Magadi MA. Understanding the gender disparity in HIV infection across countries in sub-Saharan Africa: evidence from the Demographic and Health Surveys. Soc Health Illness 2011; 33: 522-539.

12. Fasina O, Ubah JN. Pattern of pre-hospital consultation among ophthalmic patients seen in a tertiary hospital in south-west Nigeria. Afr J Med Med Sci 2009; 38: 173177.
13. Gupta N, Sachdev R, Sinha R, Titiyal JS, Tandon R. Herpes zoster ophthalmicus: disease spectrum in young adults. Middle East Afr J Ophthalmol 2011; 18: 178-182.

14. Kahloun R, Attia S, Jelliti B, Attia A Z, Khochtali S, Yahia SB, et al. Ocular involvement and visual outcome of herpes zoster ophthalmicus: a review of 45 patients from Tunisia, North Africa. J Ophthal Inflamm Infect 2014; 4: 25.

15. Van Dyk M, Meyer D. Hutchinson's sign as a marker of ocular involvement in HIVpositive patients with herpes zoster ophthalmicus. South Afr Med J 2010; 100: 172-174.

16. Zaal MJ, Völker-Dieben HJ, D'Amaro J. Prognostic value of Hutchinson's sign in acute herpes zoster ophthalmicus. Graefes Arch Clin Exp Ophthalmol 2003; 241: 187191.

17. Severson EA, Baratz KH, Hodge DO, Burke JP. Herpes zoster ophthalmicus in Olmsted county, Minnesota: have systemic antivirals made a difference? Arch Ophthalmol 2003; 121: 386-390. unrestricted, non-commercial use, reproduction and distribution in any medium provided the original source is adequately cited and credited. 